\title{
UPSIZING MANUFACTURING LINE IN VIETNAMESE INDUSTRIAL PLANTS: A SIMULATION APPROACH
}

\author{
Nguyen Dang Minh \\ University of Economics and Business, Vietnam \\ National University, Hanoi \\ Xuan Thuy Road, Cau Giay Dist \\ Hanoi, VIETNAM
}

\author{
Nguyen Dang Toan \\ Media Tenor International, Hanoi \\ Trung Tien Street, Dong Da District \\ Hanoi, VIETNAM
}

\begin{abstract}
Vietnamese industrialists have understood that simulation studies can help to form a more reliable manufacturing line than conventional methods that for the most based upon engineering experiences. However, the use of simulation has not been applied in designing the manufacturing line, and a confident method of designing a new manufacturing line or modifying the capacity of a current manufacturing line (CML) has remained a task in Vietnamese industrial plants. The main purpose of this research is to propose a new perspective of a simulation study in Vietnamese industry from an empirical point of view to implement the framework for designing a manufacturing line. The second purpose is to introduce the method and analytical procedures of modifying a CML utilized by a linear programming (LP) model for selecting. The proposed method was applied in an actual design project to confirm the feasibility of the framework.
\end{abstract}

\section{INTRODUCTION}

The Manufacturing line (ML) design plays a critical and valuable role in today's manufacturing system. Developing a more efficient ML and bringing it to realization is the main task of ML designers. In present manufacturing activities, there are two main tasks for ML designer; the first is to design a new ML and the second is to modify the current manufacturing line (CML) when the required production volume increases over the line capacity.

After conducting interviews with Vietnamese industrial manufacturers, the authors realized that manufacturing lines were traditionally designed following conventional methods and, for the most part, were based on engineering experience and simple calculations of labor utilization, machine utilization, and line productivity with constant processing data. However, the experience of designers is not always at the same level and conventional methods of design cannot simulate the actual situation of the ML because of some factors such as unevenness of processing data or machine failures. The application of a simulation study has been lacking in this field. The main reason is that no method or procedure setting a practical ML design with application of simulation study has been applied within the manufacturing society. Vietnamese designers are still hesitant to apply simulation for designing the ML, preferring conventional methods of design.

From an academic aspect, approaches related to manufacturing system design using simulation studies have been briefly reviewed as follows:

Firstly, research about the conversion of an existing manufacturing system into a new system was presented; for example, in the conversion from a job shop to a cellular manufacturing system (Durmusoglu 1993; Satoglu et al. 2006), and a US traditional manufacturing system to just-in-time system (Dyck 1998). Simulation of alternatives for simulating an old manufacturing method to a new system has been introduced in those studies; however, these studies failed to provide a method of how to design a ML based on initial information of product (production volume, line capacity, process cycle time). 
Secondly, research about the modification of the current manufacturing systems has been proposed (William et al. 2002; Grimard and Marvel 2005; Taj et al. 1998; Gujarathi et al. 2004). Such research focused on the improvement of a specific line rather than proposed a general method in solving the task of increasing current ML capacity when production volume was increasing. Furthermore, several studies with method of sizing the ML (Schniederjans and Hoffman1999; Masmoudi 2006) were also investigated. However, the proposed sizing methods in these studies were not practical in modifying CML capacity while satisfying the requirement of the process cycle time and available space constraints within a factory.

Thirdly, research analyzing specific factors of a manufacturing system has also been discussed. These studies concentrated on analyzing the impact of some detailed factors in the ML such as in breakdowns (Elleuch et al. 2007), takt time (Duanmu and Taaffe 2007) and bottlenecks (Roser, Nakano, and Tanaka $2001)$ in the system. These studies also did not provide methods of how to design or modify a ML from initial requirements.

However, the extant literature has not specifically found out the method of designing a new ML for Vietnamese industrial plants from the beginning stage with initial information of the product and the method of modifying a CML when production volume increases over the line capacity. From both the practical and theoretical point of view, the method of ML design using a simulation in a study to establish an efficient ML before fabricating and purchasing equipment is emerged in Vietnamese automobile manufacturing plants.

From the above-mentioned context, the first contribution of this research is to introduce a new framework for a ML design process from the empirical manufacturing point of view. The framework provides a general idea of how to design a new ML with a simulation study. The second contribution is to propose a distinguished method for modifying a CML when production volume increases over the line capacity. In this design process, a LP model is proposed for selecting alternatives for the simulation study. Finally, a comprehensive empirical design project in modifying an actual CML in Company A in Vietnam is introduced for ensuring the framework and understanding the important role of simulation studies in making decisions for the most efficient line. The project was completed by a project team led by the author of this article over a three year period and then handed-over to the factory in the beginning of 2013.

\section{FRAMEWORK FOR MANUFACTURING LINE DESIGN IN VIETNAMESE MANUFACTURING PLANTS}

The general concept and method for ML design projects are introduced in Figure 1. The content of this concept is explained in the following section.

\subsection{Manufacturing Line (ML) New Project Information}

The content of this concept is explained in the following section. The following information for the project is given to designers:

- ML capacity: ML capacity is initially set by top-class managers of the company, this is given to ML designer for deciding process cycle time and calculating manufacturing cost.

- Product model life: product model life is the information concerning the number of years the ML will be used for manufacturing activities; this information helps ML designers calculate the depreciation cost of investment equipment.

- Takt time of the manufacturing line: takt time is the maximum time that should be taken in producing one unit of product. Takt time can be used to decide how many workers should be used for the ML. In the new ML designs, takt time is often set at a higher percentage than process cycle time in covering some estimated fluctuations of the market demand. In case of modifying a CML, takt time is often set equal to process cycle time to save modification costs.

- Product drawing: from the technical information written in product drawing, the processing method and process sequences are decided.

With this information, the ML development can begin. 


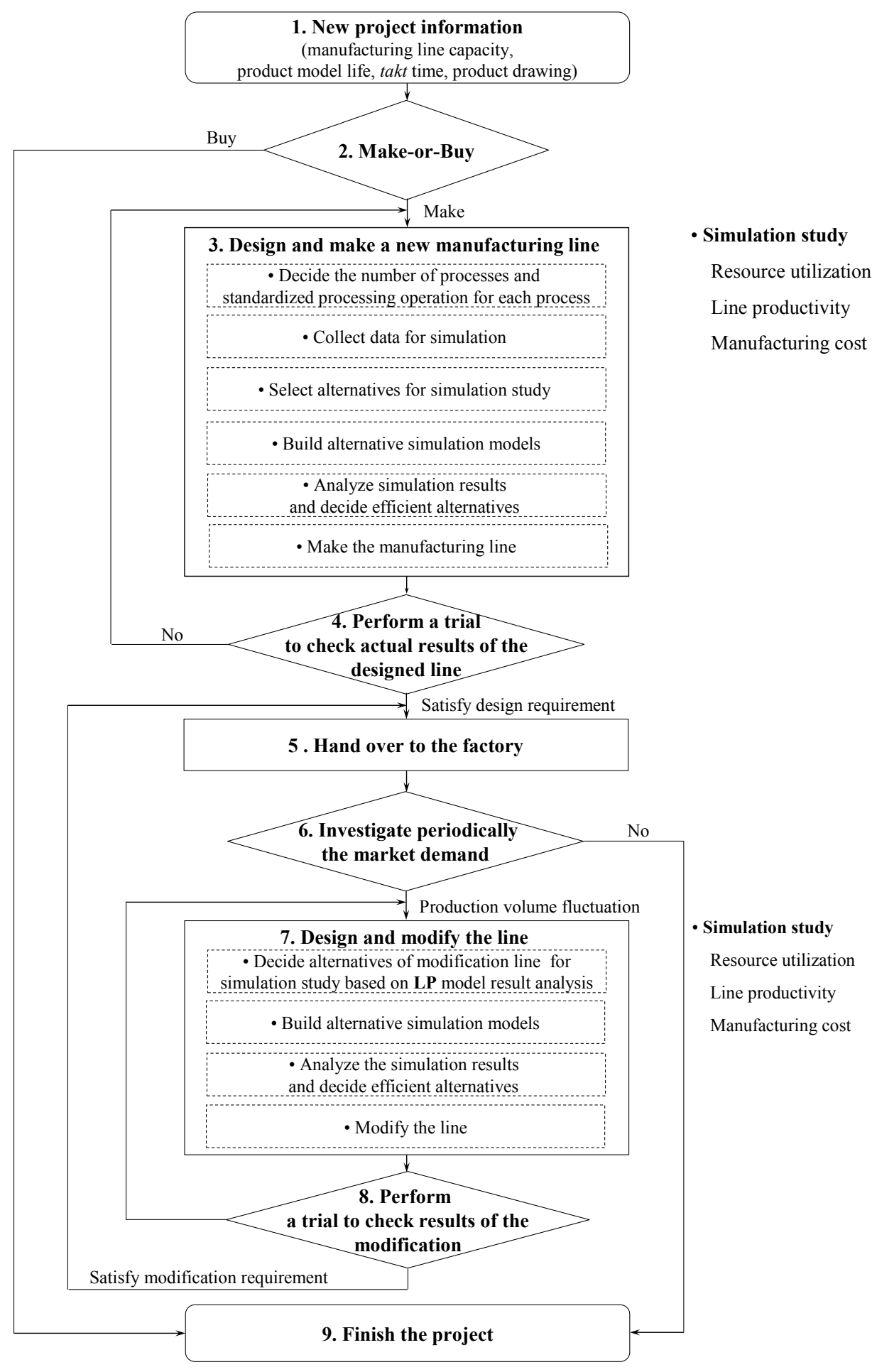

Figure 1: Framework of Manufacturing line design (MLD) for Vietnamese industrial plants

\subsection{Make or Buy}

Based on the project information, the make or buy process is investigated carefully. Make refers to made in-house and Buy refers to a product sent to an outside manufacturer. Make or Buy decision involves discussions with various related divisions in the company by project team members. In the case of a Buy de- 
cision, the manufacturing line design project will conclude, otherwise the project will progress to the next process.

\subsection{Design and Make a New Manufacturing Line}

A ML design can be developed through a simulation process. Resource utilization, line productivity and manufacturing costs are all considered in developing the most efficient line. In a manufacturing line design project, productivity is calculated as a ratio of actual output multiplied by takt time over the total operation time. This specific design process for new manufacturing lines was carried out in the following steps:

Firstly, a decision was made on the number of processes and standardized processing operations based on manufacturing technology, empirical know-how of the company, and quality and technical requirements of the product.

Secondly, data from standardized processing operations for both manual and automated process was collected from existing pilot lines (a pilot line is a line used for simulating every single standardized processing operation for a new project). Pilot project team-members joined together to simulate and measure standardized processing operations for both manual and automated processing times. Data for cost simulation was collected from the company.

Thirdly, alternative options for the new manufacturing line were decided based on the amount of workers and the type of equipment used for the line. The team investigated a manual operated manufacturing line with a manual processing machine, an automated production line with an automated machine and a hybrid line with both automated and manual machines. The manual line was advantageous in simplicity and having a lower investment in equipment costs, however, the line used more human resources than the automated line.

Fourthly, in building a simulation model, all alternatives were constructed based on information of data collection in the above-mentioned steps.

Fifthly, the simulation was analyzed based on a target of maximization in utilization of both machine and workers, maximization of line productivity (company requirement was higher than $90 \%$ ), and a minimization of manufacturing costs.

Finally, the chosen manufacturing line was constructed for trial to check the feasibility of the line.

\subsection{Check Actual Results of the Designed Line and Hand over to the Factory}

Production engineers and pilot members joined together to run the trial in checking the feasibility of the line. Worker utilization, machine utilization, and line productivity were measured and compared with simulation results. If the line satisfied a given design target, it was handed over to the factory, otherwise it was re-modified until a satisfactory result was achieved

\subsection{Investigate the Market Demand for the Product}

The production volume of the product responded from market demand and was surveyed by the marketing division periodically. In case of a decrease in production volume, takt time and a number of workers on the manufacturing line should be adjusted. The estimation of new requirements for production volume increased over the initial estimated production volume for the CML, the manufacturing line could be modified to ensure capacity.

\subsection{Design and Modification of the Line}

Firstly, the design team investigated the actual cycle time and worker cycle time of each process in order to identify excessive processing time. Secondly, the team selected alternatives of modifying the CML based on analysis process of the LP model results. Thirdly, the simulation models from the selected alternatives were constructed based on data collection in the CML and pilot line. Fourthly, the team analyzed 
the simulation results and chose an efficient alternative. Finally, after modifying the manufacturing line, design team members performed a trial to re-confirm the feasibility of the modifications.

\subsection{Check the Modification and Return to the Factory}

Worker, machine utilization, and line productivity were measured to re-confirm the feasibility of the line by project team and pilot members. Once the modifications satisfy design targets, the manufacturing line can be returned to the factory, otherwise it would be modified again until achieving positive results.

When a manufacturing line is handed-over to the factory after a positive modification, the design process has been completed.

\section{METHOD FOR SELECTING ALTERNATIVES}

The CML is described as shown in Figure 2. The CML has $n$ processes including $n_{l}$ manual process $P M_{i}$, $n_{2}$ automated process $P A_{j}, p$ processing types, (processing type is the method of manufacturing, for example, a motorbike welding manufacturing line has some processing type such as type 1 (arc weld), type 2 (nut weld), type 3 (spot weld).

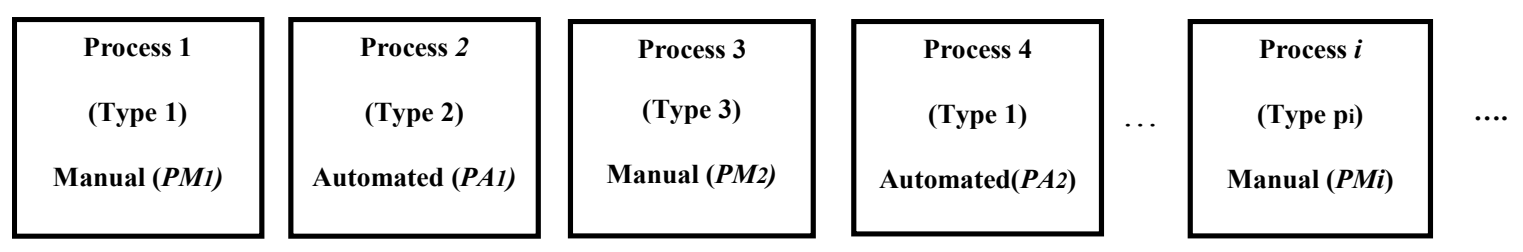

Figure 2: Image of current manufacturing line (CML)

The general idea of deciding upon alternatives for a simulation study is illustrated in Figure 3 . The processes that had process cycle time over the new required process cycle time were identified. Excessive time in the current process must be reduced to satisfy the new requirement. Because the process cycle time is combined from worker set-up time and machine processing time (Monden 1998), so that the excessive time can be reduced basically by reducing the set-up time of worker and processing time of machine. For a line modification project, worker set-up time was assumed fixed (from the empirical point of view, it was difficult to reduce worker set-up time due to it having been done in everyday improvement activities). As a result, the project team concentrated only on reducing the machine processing time. In cases where a current process is completed manually, excessive time can be reduced by moving the excessive time to a new process or change the manual process to an automated process (the processing time of an automated machine is faster than a manual machine). In cases where the current process is automated, this excessive time can be moved to a new process. Analytic procedures of LP model results were applied in making the decision for selecting the alternatives. 


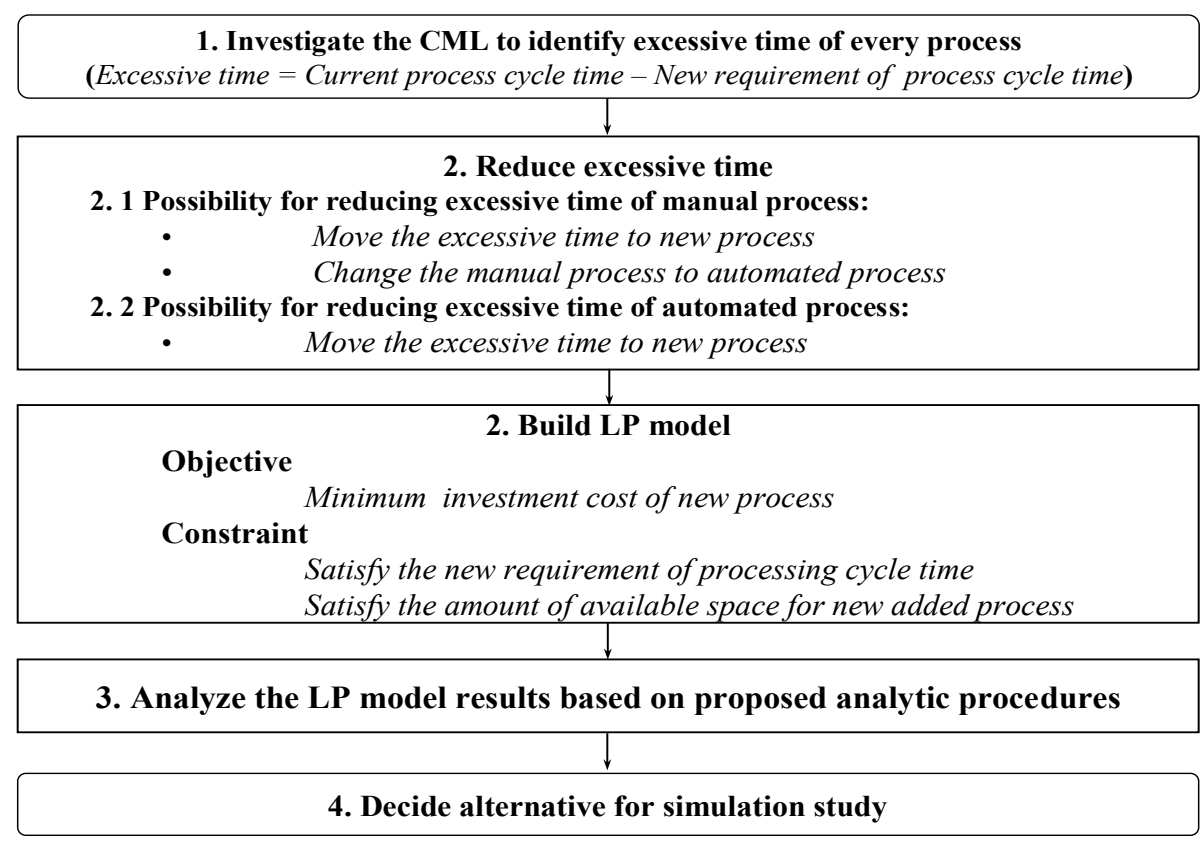

Figure 3: Method for decide alternatives for simulation study

\subsection{Linear Programming (LP) Model}

A LP model was proposed in selecting alternatives for simulation study. This model assists in solving the number of new processes that should be increased while minimizing the total equipment investment costs in equation (1) below. The expressions in (2) and (3) set the condition that available processing time of new processes has to satisfy the excessive time of the current process. The space constraint for the new process presented in (4) shows the condition of total space occupied by new processes and must satisfy the available space within the factory.

Minimize

$$
z=\sum_{i=1}^{n 1} a_{i} x_{i}+\sum_{j=1}^{n 2} b_{j} y_{j}
$$

Subject to:

$$
\begin{aligned}
& t_{m i} x_{i} \geq k_{m i} e_{m i} \\
& t_{a j} y_{j} \geq k_{a j} e_{e j} \\
& \sum_{i=1}^{n 1} x_{i}+\sum_{j=1}^{n 2} y_{j} \leq q
\end{aligned}
$$

where:

$x_{i}, y_{j}$ : number of new processes should be increased for every current manual and automated process respectively $\left(x_{i}, y_{i} \geq 0\right.$, real $)$ (process).

$a_{i}, b_{j} \quad$ : investment cost for increasing one process $x_{i}$ and $y_{j}(1000 \$)$

$t_{m i}, t_{a j}:$ available machine processing time for the new process $x_{i}, y_{j}(\mathrm{sec})$

$$
\begin{aligned}
t_{m i} & =t_{r}-s_{m i} \\
t_{a j} & =t_{r}-s_{a j}
\end{aligned}
$$

$t_{r} \quad:$ new requirement of process cycle time of the modification line (sec)

$s_{m i}, s_{a j}:$ set up time of workers for the new process $x_{i}, y_{j}(\mathrm{sec})$

$e_{m i} e_{a j} \quad$ : excessive time of the current process $P M_{i}, P A_{j}(\mathrm{sec})$ 
$k_{m i}, k_{a j}:$ coefficient indicating the differences of processing speed between current machine and newly added machines in the process $P M_{i}, P A_{i \cdot}\left(k_{m i}, k_{a j} \geq 0\right)$

$q \quad$ : amount of available space for new added process $(q>0$, integer $)$

The LP model is built into two cases when a new process is considered as manual and automated respectively. Data of processing time that uses the LP model is considered as constant data quoted from the average results of the current line.

\subsection{Analytic Procedures for the linear Programming (LP) Model Results}

Based on the results of the LP model simulation, the following empirical engineering procedures were proposed for selecting the new process and estimating the number of workers for the selected alternatives.

1. Combining processes $x_{i}$ and $y_{j}$ to one process if processing type of $x_{i}$ and $y_{j}$ were the same, and satisfy condition given in (7).

$$
x_{i}+y_{j} \leq 1
$$

2. Changing the current manual process to automated process if the current manual process satisfied the new requirement of processing time condition expressed in (8). Furthermore if the newly modified automated process still had capacity, the process was combined with other automated process that had the same processing type given in condition of (9).

$$
\begin{array}{r}
\left(t_{m i}+e_{m i}\right) k_{m i} \leq t_{m i} \\
\frac{\left(t_{m i}+e_{m i}\right) k_{m i}}{t_{m i}}+y_{i} \leq 1
\end{array}
$$

3. Combining the excessive processing time of the inspection and repair process with its preceding and subsequent process (same concept with condition given in (7)).

4. Number of workers for the alternative was decided after selecting a number of new processes. Necessary workers were calculated as total manual processing time and waking time divided by the process cycle time given in (10)

$$
n w=\frac{\sum_{1}^{g 1}\left(s_{m i}+t_{p i}\right)+\sum_{1}^{g 2} s_{a j}+\sum_{1}^{g 1+g 2} t_{w i}}{t_{r}}
$$

where:

$n w \quad$ : number of estimated worker ( $n w>0$, integer)

$g_{1}, g_{2}:$ total manual and automated processes of the modification line (process)

$s_{m i}, s_{a j}:$ set up time for manual process and automated process $(\mathrm{sec})$

$t_{p i} \quad$ : manual processing time of worker for manual process $(\mathrm{sec})$

$t_{w i} \quad$ : estimated walking time of worker for every process $(\mathrm{sec})$

\section{APPLY PROPOSED METHOD TO AN ACTUAL DESIGN PROJECT}

In this section, an actual project of modifying a CML in Company $A$ is introduced in order to enhance understanding of proposed method.

The modification of increasing line capacity of a current cellular welding ML was requested by the Production Planning Division. The line has been utilized for three years with information on the modification is shown in Table 1. Production volume of the modification line was requested to increase to 17000 units/month, takt time and process cycle time were reduced to 58 seconds (as mention in previous section, for the modification of CML, the new process cycle time and worker cycle time was also set equal to required takt time)

Table 1: Information for the modification line 
Minh and Toan

\begin{tabular}{|l|c|c|}
\hline Items & Current manufacturing line & New requirement of the modification line \\
\hline Line capacity & 13500 units/month & $\mathbf{1 7 0 0 0}$ units/month \\
\hline Process cycle time & 71 seconds & $\mathbf{5 8}$ seconds - \\
\hline Process takt time & 98 seconds & $\mathbf{5 8}$ seconds \\
\hline
\end{tabular}

\subsection{Running Heads}

The concept of the CML is shown in Figure 4, which followed the just-in-time manufacturing method (Monden1998) in which parts (part 1, part 2, part 3, and part 4) were fed into the system at a constant rate base on takt time. The CML was operated by 3 workers that worker 1 was in charge of process 1 (manual nut welding $\mathrm{PM}_{1}$ ) and process 2 (automated arc weld $\mathrm{PA}_{1}$ ), worker 2 was responsible for process 3 (manual spot weld $\mathrm{PM}_{2}$ ) and process 4 (automated arc weld $\mathrm{PA}_{2}$ ), worker 3 was in charge of process 5 (additional automated spot weld $\mathrm{PA}_{3}$ ) and process 6 the (final manual inspection and repair $\mathrm{PM}_{3}$ ).

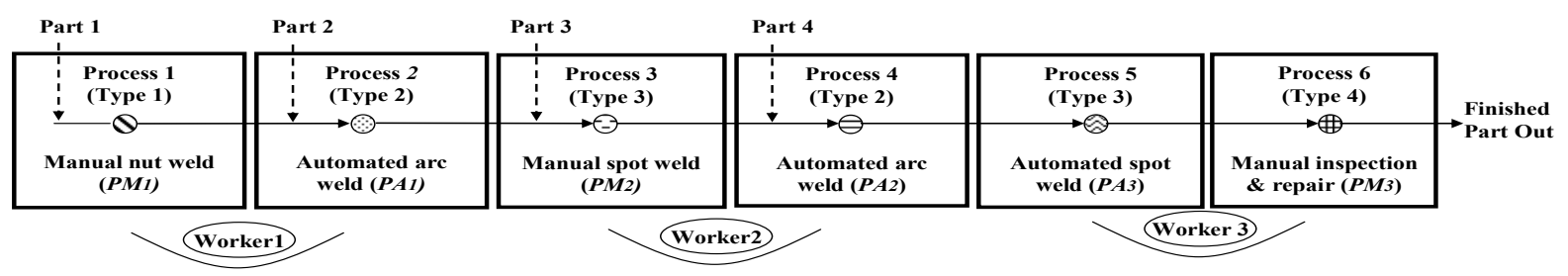

Figure 4: Concept of the current manufacturing line

Actual process cycle time of each process were measured for identifying excessive time (13 seconds, 10 seconds, 13 seconds, 10 seconds, 12 seconds, 10 seconds for process $1,2,3,4,5,6$ respectively).

\subsection{Linear Programming (LP) Model}

LP model for the case one (new process was considered as manual process) and case 2 (new process was considered as automated process) was given as:

Min: $z=60^{*}\left(150^{* *}\right) x_{1}+78^{*}\left(170^{* *}\right) x_{2}+40^{*}\left(120^{* *}\right) x_{3}+80^{*}\left(180^{* *}\right) y_{1}+85^{*}\left(180^{* *}\right) y_{2}+75^{*}\left(165^{* *}\right) y_{3}$

Subject to:

$$
\begin{aligned}
& 48 x_{1} \geq 1^{*}\left(0.67^{* *}\right) \times 13 \\
& 42 x_{2} \geq 1^{*}\left(0.55^{* * *}\right) \times 13 \\
& 42 x_{3} \geq 1^{*}\left(0.8^{* *}\right) \times 10 \\
& 43 y_{1} \geq 1.5^{*}\left(1^{* *}\right) \times 10 \\
& 45 y_{2} \geq 1.5^{*} \cdot\left(1^{* *}\right) \times 10 \\
& 45 y_{3} \geq 1^{*}\left(1.5^{* *}\right) \times 12 \\
& x_{1}+x_{2}+x_{3}+y_{1}+y_{2}+y_{3} \leq 2
\end{aligned}
$$

$(*)$ : parameters for case $1 ;(* *)$ : parameters for case 2

All parameters using the LP model was quoted from CML of the company.

\subsection{Analyze LP Model Results and Decide Alternatives for a Simulation Study}

The LINDO programming software (Schrage 1997) was applied to assist in solving the LP model in both case 1 and case 2 . Results of the new process $\left(x_{1} x_{2}, x_{3}, y_{1}, y_{2}, y_{3}\right)$ are given in Table 2.

Table 2: LP results

\begin{tabular}{|c|c|r|r|r|r|c|c|}
\hline Type & Type 1 & \multicolumn{2}{|c|}{ Type 2 } & \multicolumn{2}{|c|}{ Type 3 } & Type 4 & $z$ \\
\hline Current process for the CML & Process 1 & Process 2 & Process 4 & Process 3 & Process 5 & Process 6 \\
\hline Results & $x_{1}$ & $y_{1}$ & $y_{2}$ & $x_{2}$ & $y_{3}$ & $x_{3}$ & \\
\hline
\end{tabular}


Minh and Toan

\begin{tabular}{|l|l|l|l|l|l|l|l|}
\hline Case 1 & 0.27 & 0.34 & 0.33 & 0.30 & 0.40 & 0.23 & 136.2 \\
\hline Case 2 & 0.18 & 0.23 & 0.22 & 0.17 & 0.27 & 0.19 & 204.8 \\
\hline
\end{tabular}

Based on the analytic procedures of (7), (8), and (9) given in section 3.2 of this paper, the final analysis results for reducing excessive processing time are summarized as:

- Current process 1 (type 1): change to automated nut weld process

- Current process 2 and process 4 (type 2): move the excessive processing time of these processes to one new arc weld process (this new arc process can be selected as manual process for Alternative 1 and automated for Alternative 2).

- Current process 3 (type 3): change to automated spot weld process.

- Current process 5 (type 3): move the excessive processing time to process 3 when process 3 was changed to automated process

- Current process 6 (type 4): move excessive inspection time to the new arc weld process (because the arc weld process still has capacity).

The estimation of the number of workers for both alternatives was decided based on the method shown in step (10). The average data for the calculation is referred from Table 3. The calculation results for case 1 and case 2 are given as: $n w_{\text {alternative }}=(206 / 58=3.6) ; n w_{\text {alternative } 2}=(171 / 58=2.9)$. As a result, four workers were selected for alternative 1 and three workers were estimated for alternative 2 .

Table 3: Parameters of worker manual processing and walking time (seconds)

\begin{tabular}{|c|c|c|c|c|c|c|c|c|}
\hline & New process for the modification & Process 1 & Process 2 & Process 3 & Process 4 & Process 5 & Process 6 & Process 7 \\
\hline \multirow{3}{*}{ 安 } & Manual set up time & 10 & 16 & 16 & 16 & 13 & 13 & 13 \\
\cline { 2 - 9 } & Manual processing time & & & & & & 35 & 39 \\
\cline { 2 - 9 } & Estimation of walking time & 5 & 5 & 5 & 5 & 5 & 5 & 5 \\
\hline \multirow{2}{*}{ ¿ } & Manual set up time & 10 & 16 & 16 & 16 & 13 & 13 & 13 \\
\cline { 2 - 9 } & Manual processing time & & & & & & & 39 \\
\cline { 2 - 9 } & Estimation of walking time & 5 & 5 & 5 & 5 & 5 & 5 & 5 \\
\hline
\end{tabular}

Both alternative 1 and alternative 2 have its own advantages. Investment costs in the process of alternative 1 were cheaper while the labor costs for alternative 2 were lower. Alternative 1 and case 2 were selected for a simulation study.

\subsection{Data Collection for Simulation Study}

The data for each standardized operation in seven processes of both alternatives was collected by the project team-members. The data of the modified process (process 1, process 3 , and process 6 ) was collected from pilot line. The data in the remaining process 2, 5 and 7 was collected from the CML. Besides the operation time, the following information was also obtained from the factory: there were two production work shifts consisting of eight hours each. In each shift, the worker was allowed one hour for a meal and two 15-minute tea breaks. Average unplanned failure on the manufacturing line and repair rates in the final inspection process quoted from past data from the factory. The sample size of each standardized processing operation was 50. The final results of collected data are summarized in Table 4.

\subsection{Simulation Model}

Simulation models were built using the software Arena (Kelton, Sadowski and Sturrock 2007). Input parameters and simulation run conditions were set-up based on information explained section 4.4 above. Parts were fed into the system at a constant rate based on required takt time. The simulation run time was set to 100 working days with 100 replications. In this project, a simulation model of each alternative was also built and executed separately due to resource differentials. An example of a process flow for alternative 2 is illustrated in Figure 5. 


\section{Minh and Toan}

\subsection{Analyze Simulation Results and Decide an Efficient Alternative}

The purpose of the simulation study for this project is to reveal which alternative satisfies the design requirements included concerns with higher resource utilization, over $90 \%$ of line productivity, and lower manufacturing costs. Simulation results from each of the alternative are summarized in table 5.

Table 4: Parameters for simulation model (seconds)

\begin{tabular}{|c|c|c|c|c|c|c|c|}
\hline Standardized operation & Process 1 & Process 2 & Process 3 & Process 4 & Process 5 & Process 6 & Process 7 \\
\hline $\begin{array}{l}\text { Load part on jig by } \\
\text { worker }\end{array}$ & $\operatorname{TRIA}(4,5,6)$ & $\operatorname{TRIA}(8,9,10)$ & $\operatorname{TRIA}(8,9,10)$ & $\operatorname{TRIA}(8,9,10)$ & $\operatorname{TRIA}(5,6,7)$ & $\operatorname{TRIA}(5,6,7)$ & $\operatorname{TRIA}(5,6,9)$ \\
\hline $\begin{array}{l}\text { Slide finished part to } \\
\text { next process by worker }\end{array}$ & $\operatorname{TRIA}(3,5,6)$ & $\operatorname{TRIA}(5,7,8)$ & $\operatorname{TRIA}(5,7,8)$ & $\operatorname{TRIA}(5,7,8)$ & $\operatorname{TRIA}(5,7,8)$ & $\operatorname{TRIA}(5,7,8)$ & $\operatorname{TRIA}(5,7,9)$ \\
\hline $\begin{array}{l}\text { Automated weld by ro- } \\
\text { bot }\end{array}$ & $\operatorname{UNIF}(43,45)$ & UNIF $(40,42)$ & $\mathrm{UNIF}(38,40)$ & UNIF $(41,43)$ & $\operatorname{UNIF}(41,43)$ & $\begin{array}{c}\mathrm{UNIF}(15,30) \\
(* *)\end{array}$ & \\
\hline Manual weld by worker & & & & & & $\begin{array}{c}\text { TRIA(26,29,36) } \\
(*)\end{array}$ & \\
\hline Inspection by robot & & & & & & $\begin{array}{c}\mathrm{UNIF}(10,20) \\
(* *)\end{array}$ & \\
\hline $\begin{array}{l}\text { Manual inspection by } \\
\text { worker }\end{array}$ & & & & & & $\begin{array}{c}\text { TRIA(10,12,15) } \\
(*)\end{array}$ & $\operatorname{TRIA}(35,37,50)$ \\
\hline $\begin{array}{l}\text { Manual repair by worker } \\
\text { (Repair rate }=10 \%)\end{array}$ & & & & & & & $\operatorname{TRIA}(25,30,35)$ \\
\hline $\begin{array}{l}\text { Worker walk in process } \\
\text { for alternative } 1\end{array}$ & \multicolumn{7}{|c|}{$\begin{array}{l}\text { Worker1:TRIA }(14,16,20) \text {; Worker2: TRIA }(14,16,20) \text {; Worker3: TRIA }(2,3,4) \text {; Worker4: TRIA }(2,3,4) \quad(*) \\
\text { Worker 1: TRIA }(14,16,20) \text {; Worker } 2 \text { TRIA }(14,16,20) \text {; Worker 3: TRIA }(2,3,4) \\
(* *)\end{array}$} \\
\hline Unplanned break failure & \multicolumn{7}{|c|}{ Time to Failure: TRIA $(5400,7200,10800)$; Failure time: TRIA $(50,70,90)$} \\
\hline
\end{tabular}

Notation: TRIA=Triangular, $\mathrm{UNIF}=\mathrm{Uniform},(*)$ : for alternative $1,(* *)$ : for alternative 2

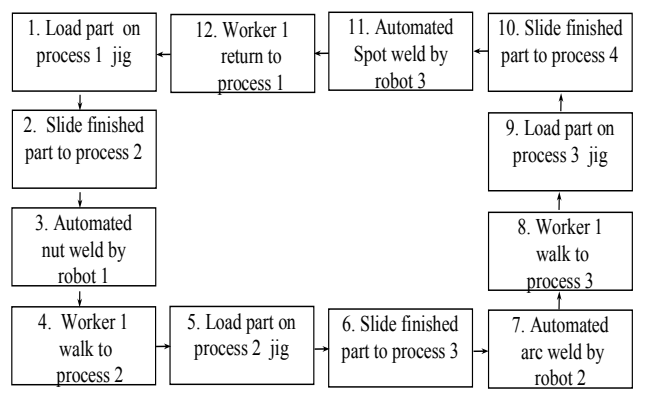

a) Worker 1

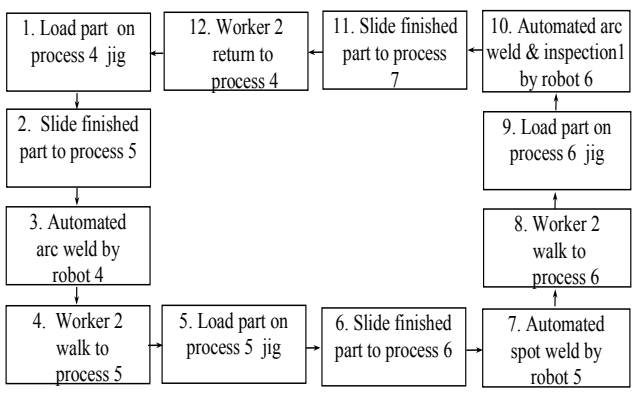

b) Worker 2

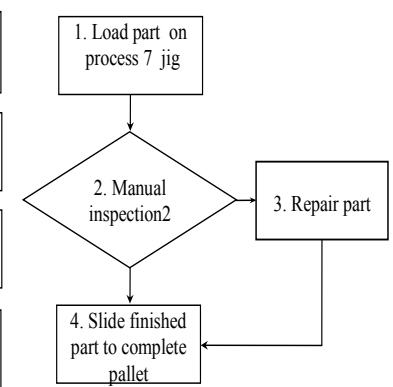

c) Worker 3

Figure 5: Example of process flow of alternative 2 for simulation model

Table 5: Simulation results

\begin{tabular}{|c|c|c|c|c|c|c|c|c|c|c|c|c|c|c|}
\hline & \multicolumn{12}{|c|}{ Resource utilization } & \multirow{3}{*}{ 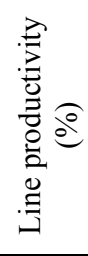 } & \multirow{3}{*}{ 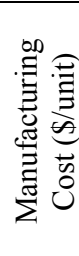 } \\
\hline & \multicolumn{5}{|c|}{ Worker utilization $(\%)$} & \multicolumn{6}{|c|}{ Robot utilization (\%) } & \multirow[b]{2}{*}{ 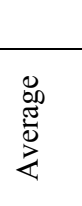 } & & \\
\hline & $\frac{\dot{\bar{d}}}{\frac{y}{0}-}$ & $\begin{array}{l}\frac{N}{\overline{0}} \\
\frac{\bar{y}}{\overline{0}} \\
\dot{3}\end{array}$ & $\begin{array}{l}m \\
\dot{\overrightarrow{0}} \\
\frac{y}{\dot{0}} \\
\dot{3}\end{array}$ & 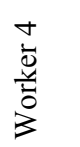 & 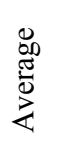 & 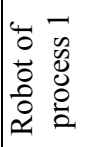 & $\begin{array}{ll}4 & \overline{0} \\
0 & 0 \\
0 & 0 \\
0 & 0 \\
0 & 0 \\
0 & 0 \\
\simeq & 0\end{array}$ & 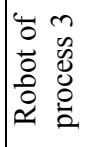 & 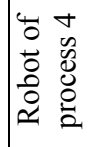 & 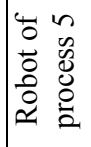 & 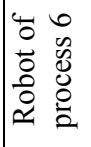 & & & \\
\hline Alt 1 & 87.9 & 94.1 & 98.4 & 95.4 & 94.4 & 75.8 & 70.7 & 67.2 & 72.4 & 72.4 & - & 71.7 & 96.4 & 14.9 \\
\hline Alt 2 & 98.4 & 98.3 & 98.5 & - & 98.4 & 75.8 & 70.7 & 67.2 & 72.4 & 72.4 & 73.8 & 72.1 & 98.3 & 13.2 \\
\hline
\end{tabular}




\section{Minh and Toan}

The alternative one was designed to employ four workers and five robots with an average utilization of $94.4 \%$ and $71.7 \%$ respectively. The alternative two used three workers and six robots with an average utilization of $98.4 \%$ and $72.1 \%$ respectively. The results showed that the alternative two achieved higher resource utilization.

The line productivity of each alternative was also calculated from a simulation model. Both alternatives achieved the design requirement (higher than 90\%), however, the alternative two was more advantageous.

Manufacturing costs in both alternatives also were estimated by data quoted from the company's finance and accounting division. The final results were summarized with the manufacturing costs of alternative two being lower because labor costs in the alternative one were higher than the depreciation costs in the alternative two.

In summarizing the simulation study, the alternative two achieved higher resource utilization and satisfied the design requirement for productivity and lower manufacturing costs. The alternative two was, therefore, selected to modify the manufacturing line.

\subsection{Check Actual Results of the Modification and Hand over the Factory}

Automated robots and associated equipment were purchased and installed, and then a final trial was completed by project-team members after adjusting the machines, robots and parts at good quality condition. Trials were carried out for three working days in order to re-confirm the feasibility of the line (due to time and budget constraints, the team could not run a trial as long as the simulation conditions). Actual trial results of the resource utilization and line productivity were very close to the simulation results (average utilization was $98 \%$ for workers and $72 \%$ for robots, while the line productivity was $98 \%$ ).

Average actual results of the process cycle time and worker cycle time were also measured (process cycle time were $57,57.5,57.5,56.5,57,57$ and 56.5 seconds for process $1,2,3,4,5,6,7$ respectively; worker cycle time were $57,57.5$, and 56.5 seconds for worker 1 , worker 2 , worker 3 respectively). The actual results show that the chosen manufacturing line satisfies the design target ( 58 seconds), the line could be returned to the factory for manufacturing activities.

The proposed method was useful in investigating the feasibility of modifying a ML. In this project, the simulation study also assisted in reducing project time in the design process $(10 \%$ of the total designed time) and saved costs in line modification ( $7 \%$ of the total equipment investment costs) in comparison with the conventional design method in previous projects.

\section{CONCLUSIONS}

A framework in ML designs in Vietnamese manufacturing plants was introduced to show the contribution of a simulation study in the whole design process. The method for combining a LP model and simulation investigation was helpful for ML designers in dealing with the ML modification task. The proposed framework and designed method have opened up new potential for ML design for the application of simulation models in the Vietnamese automobile manufacturing plants.

A simulation study not only can help engineers discover better options for developing efficient equipment but can also save time and money from mistakes in redesigning and re-fabricating equipment in comparison with conventional methods that for the most part were based on engineering experience. However, limitations in the application of a simulation study in actual ML design still exist. For instance, the company needs to organize training program for engineers to obtain professional knowledge in building simulation model. The concept of the ML design in this research can be extended to other manufacturing areas in future research.

\section{REFERENCES}

Dyck, H., Johnson A. J. 1988. "Transforming a traditional manufacturing system into a just-in-time system with kanban". Proceedings of the 1988 Winter Simulation Conference 616-623. 
Duanmu, J. and Taaffe K. 2007. "Measuring manufacturing throughput using takt time analysis and simulation". Proceedings of the 2007 Winter Simulation Conference 1633-1640.

Durmusoglu, M. B. 1993. "Analysis of the conversion from a job shop system to a cellular manufacturing system”. International Journal of Production Economics Vol. 30-31: 427-436.

Elleuch, M., Masmoudi F., Ben Bacha H., and Maalej A. Y. 2007. "Simulation of manufacturing cells with unreliable machines". International Journal of Simulation Modeling Vol.6, No.1: 5-12.

Grimard, C. and Marvel J. H. 2005. "Validation of the Re-design of a manufacturing work cell using simulation". Proceedings of the 2005 Winter Simulation Conference 1386-1391.

Gujarathi, N. S., Ogale R. M., and Gupta T. 2004. "Production capacity analysis of a shock absorber assembly line using simulation". Proceedings of the 2004 Winter Simulation Conference 1213-1217.

Kelton, W. D., Sadowski R. P., and Sturrock D. T. 2007. Simulation with ARENA. McGraw-Hill, New York.

Masmoudi, F. 2006. "Sizing manufacturing cell machines base on the simulation and an expert system". International Journal of Simulation Modeling Vol.5, No.2: 45-55.

Monden, Y. 1998. Toyota Production System: An Integrated Approach to Just-In-Time. Industrial Engineering and Management Press, Georgia.

Roser, C., Nakano M., and Tanaka M. 2001. "A practical bottleneck detection method". Proceedings of the 2001 Winter Simulation Conference 949-953.

Satoglu, S. I., Durmusoglu M. B., and Dogan I. 2006. "Evaluation of the conversion from central storage to decentralized storages in cellular manufacturing environments using activity-based costing". International Journal of Production Economics Vol.103: 616-632.

Schniederjans, M. J. and Hoffman. J. J. 1999. "Downsizing production/operations with multi-objective programming". International Journal of Operations and Production Management Vol.19, No.1: 7991.

Schrage, L. 1997. Optimization model with LINDO. International Thomson Publishing, New York.

Taj, S., Cochran D. S., Dura J. W., and Linck J. 1998. "Simulation and production planning for manufacturing cells". Proceedings of the 1998 Winter Simulation Conference 973-977.

William, G. S., Thomas N. M., and Eileen M. V. A. 2002. "Equipment replacement decisions and lean manufacturing". Journal of Robotics and Computer Integrated Manufacturing Vol.18: 255-265.

\section{AUTHOR BIOGRAPHIES}

NGUYEN DANG MINH is Director of Research, Cooperation and Development Department, University of Economics and Business, Vietnam National University, Hanoi. His research interests are in the area of securities and investment analysis, optimization of make or buy decision making process, production line design using simulation and multiple economic factors. His email address is nguyendangminh@hotmail.com.

NGUYEN DANG TOAN is a researcher at Media Tenor Vietnam and Vietnam Development Forum. His research interests are Monte Carlo methods with a specific focus on Corporate Valuation and Stock Valuation. His email address is nguyendangtoan1984@yahoo.com. 